Re-submitted to: Chemosphere

Date: 22 Apr 2006

\title{
Electrochemical degradation of 4-chlorophenol at nickel-antimony doped tin oxide electrode
}

\author{
Y. H. Wang ${ }^{\text {a }}$ K. Y. Chan ${ }^{\mathrm{a}^{*}}$, X. Y. Li ${ }^{\mathrm{b} *}$ and S. K. So ${ }^{\mathrm{c}}$ \\ a Department of Chemistry, The University of Hong Kong, Pokfulam Road, \\ Hong Kong, China \\ ${ }^{\mathrm{b}}$ Environmental Engineering Research Centre, Department of Civil Engineering, \\ The University of Hong Kong, Pokfulam Road, Hong Kong, China \\ ${ }^{\mathrm{c}}$ Department of Physics, Hong Kong Baptist University, Kowloon Tong, \\ Hong Kong, China
}

$\begin{array}{ccll}{ }^{*} \text { Corresponding Authors: } & \text { Chan K.Y. } & \text { Phone: } & \text { (852) } 28571586 \\ & \text { Fax: } & \text { (852) } 28597917 \\ & \text { E-mail: } & \underline{\text { hrsccky@hku.hk }} \\ & & \\ \text { Li X.Y. } & \text { Phone: } & \text { (852) } 28592659 \\ & \text { Fax: } & \text { (852) } 25595337 \\ & \text { E-mail: } & \text { xlia@hku.hk }\end{array}$

Running head: Electrochemical degradation of chlorophenol. 
Abstract: The effectiveness of a novel nickel-antimony doped tin oxide electrode for electrochemical degradation of organic pollutants was investigated using 4-chlorophenol (4$\mathrm{CP}$ ) as a model toxic organic. The experimental results demonstrate that the optimal $\mathrm{Ni}$ 4 content was at $\mathrm{Ni}: \mathrm{Sn}=1: 500$ in atomic ratio in the precursor coating solution, whereas the Sb:Sn ratio was set at 8:500. Using the electrode prepared with the optimal Ni doping ratio for 4-CP degradation, the charge-based efficiencies were up to $89 \mu \mathrm{g} \mathrm{C}^{-1}$ for 4-CP destruction and $15 \mu \mathrm{g} \mathrm{C}^{-1}$ for TOC removal, which were considerably higher than the efficiencies 8 observed for other electrodes. It is suggested that the enhancement of the electrode for electrochemical oxidation of organics could be attributed to the production of hydroxyl radicals in anodic water electrolysis.

12 Keywords: Antimony-nickel doped tin dioxide electrode, 4-chlorophenol, electro-oxidation, organic degradation, wastewater treatment. 


\section{Introduction}

Direct electrochemical (EC) degradation is one of the many advanced oxidation processes for removing toxic organic contaminants in industrial wastewater. The EC process

4 has attracted considerable research interest in recent years because of its simplicity in operation, robustness in system configuration (Johnson et al., 1991; Comninellis, 1994) and reliable performance for a wide variety of toxic organics (Comninellis and Pulgarin, 1991; Kotz et al., 1991; Zhi et al., 2003). The most important components of an EC system are the

8 electrodes, particularly the anode. Different electrode materials show diverse effectiveness in organic oxidation (Sharifian and Kirk, 1986; Rodger et al., 1999; Michaud et al., 2003; Borras et al., 2004). Anodes coated with $\mathrm{PbO}_{2}, \mathrm{SnO}_{2}$ and doped diamond have a high oxygen evolution potential (Stucki et al., 1991; Lipp and Pletcher, 1997; Grimm et al, 1998; Iniesta et al., 2001; Quiroz et al., 2005). These materials can hinder the thermodynamically favored oxygen evolution reaction and hence improve the efficiency for EC organic destruction and degradation (Vicent et al., 1998; Johnson et al., 1999; Feng and Li, 2003; Quiroz et al., 2003). Potential leaching of toxic lead from a $\mathrm{PbO}_{2}$ anode would prevent its practical application ( $\mathrm{Li}$

16 et al., 2005). In comparison to doped diamond, an electrode coated with $\mathrm{SnO}_{2}$ is easier to prepare and more cost-effective (Pulgarin et al., 1994; Correa-Lozano et al., 1996; Houk et al., 1998). Due to its high electrical resistance, tin dioxide is often doped with Sb to improve its conductivity (Correa-Lozano et al., 1996; Johnson et al., 1999; Feng and Li, 2003). There are other attempts to dope the tin oxide electrode with other elements to increase its reactivity toward organic oxidation (Johnson et al., 1999; Feng and Li, 2003).

Recently, it was found that a $\mathrm{SnO}_{2}$ electrode doped with antimony can generate ozone via electrolysis in the liquid phase with a high current efficiency (Cheng and Chan, 2004).

24 The Sb:Sn atom ratio was found to be 16:1000 for maximum generation of ozone while earlier EC investigations of Sb-SnO $\mathrm{S}_{2}$ had used much higher Sb concentrations. More recently, 
it was observed that doping of trace nickel can further enhance the ozone generation efficiency (Wang et al., 2005). It was worth investigating these effective ozone generating electrodes for their EC degradation of organic pollutants since there appears to be a

4 correlation of the two processes. The novel Sb-Ni co-doped $\mathrm{SnO}_{2}$ electrode has an onset anodic potential as high as $1.7 \mathrm{~V}$ versus $\mathrm{Ag} / \mathrm{AgCl}$ in $0.1 \mathrm{M}$ sulfuric acid. This would allow EC reactions to take place, besides oxygen evolution. Therefore, this type of electrode is expected to have a higher reactivity for direct anodic oxidation of contaminants. It could be

8 utilized for effective detoxification and degradation of toxic organic pollutants in industrial effluents.

4-Chlorophenol (4-CP) is a toxic and non-biodegradable organic compound that is widely used for the production of dyes, drugs, pesticides and fungicides. 4-CP can be found in high quantity in the wastewater from various industrial sectors (Theurich et al., 1996). As a typical organic toxin, 4-CP has often been used in wastewater treatment studies (Johnson et al., 2000; Zanta et al., 2003; Canizares et al., 2003; Borras et al., 2004). The degradation of 4CP by an EC process had been investigated with a platinum anode (Brillas et al., 1998), Sn-

16 Sb-Ti-Ru mixed metal oxide anode (Johnson et al., 1999), and boron-doped diamond electrode (Rodrigo et al., 2001). Complete degradation of 4-CP by EC process was not usually observed. In this work, 4-CP is selected as a model toxic pollutant to evaluate the effectiveness of the novel Ni-Sb doped tin oxide electrode for EC degradation of organic pollutants.

\section{Materials and Methods}


The electrodes were prepared by coating of Sn-Sb-Ni on a titanium (Ti) substrate with an alcohol solution containing $\mathrm{SnCl}_{4} \cdot 5 \mathrm{H}_{2} \mathrm{O}$ (98\%, $\left.\mathrm{ABCR}\right), \mathrm{SbCl}_{3}(99.5 \%, \mathrm{BDH})$ and $\mathrm{NiCl}_{2} \cdot 6 \mathrm{H}_{2} \mathrm{O}$ (98\%, Merck) precursors followed by pyrolysis at $500^{\circ} \mathrm{C}$. The preparation

4 procedure is the same as described in our previous reports (Cheng and Chan, 2004; Wang et al., 2005). The Ti substrate (99.5\%) is a $0.5 \mathrm{~mm}$ foil supplied by Good Fellow Inc., U.K. For making an electrode, a $0.8 \mathrm{~cm}$ x $0.8 \mathrm{~cm}$ titanium foil spot-welded with a $1 \mathrm{~mm}$ diameter $\mathrm{Ti}$ wire (99.5\%, Good Fellow) was treated in $10 \%$ boiling oxalic acid for 1 h, washed with

8 distilled water, and dried naturally. The Sb was present in the coating solution at 1.6 atom\% relative to Sn, which was determined from our previous work to have a maximum electrolytic ozone generation (Wang et al., 2005). A series of Ni concentrations at $0 \%, 0.2 \%, 0.5 \%$ and 1.0 atom\% relative to $\mathrm{Sn}$ were chosen to prepare the precursor for the $\mathrm{Sb}-\mathrm{Ni}$ co-doped $\mathrm{SnO}_{2}$ coating and the electrodes were named as Ni0, Ni2, Ni5 and Ni10, respectively. The dipcoating and pyrolysis procedure was repeated seven times. In the final heating step, the electrodes were annealed at $500^{\circ} \mathrm{C}$ for a longer duration of $1 \mathrm{~h}$.

\subsection{Electrochemical experiment}

The EC degradation of 4-CP was conducted in a standard $3.5 \mathrm{~mL}$ quartz cell used for UV spectrophotometric measurement. The top cover of the UV-cell had three slots for installation of the anode, a counter electrode, and a reference electrode. The three electrodes were connected to a potentiostat (Radiometer Copenhagen/Dynamic-Eis Voltalab PGZ301), which controlled the potential of the electrolysis experiment. The Sb-Ni doped $\mathrm{SnO}_{2}$ anode was placed flat on the bottom of the UV cell. The cathode was a platinum foil $7 \mathrm{~mm}$ in diameter placed in the top region of the cell next to the sidewall. The distance between the 24 anode and cathode was about $1.5 \mathrm{~cm}$. $\mathrm{An} \mathrm{Ag} / \mathrm{AgCl}$ wire was used as the reference electrode, which was placed immediately adjacent to the anode. The cell was filled with $3 \mathrm{~mL}$ of the 
model solution containing $8 \mathrm{mM}\left(1028 \mathrm{mg} \mathrm{L}^{-1}\right)$ of $4-\mathrm{CP}$ and $0.1 \mathrm{M} \mathrm{H}_{2} \mathrm{SO}_{4}$ and the medium of EC degradation had a pH of 1.0. The model solution of 4-CP (Aldrich) was prepared by using $18 \mathrm{M} \Omega \mathrm{cm}^{-1}$ water purified by a Millipore Milli-Q system. The EC degradation experiments were performed at a constant current of $4 \mathrm{~mA}$, producing an anodic current intensity of 3.1 $\mathrm{mA} \mathrm{cm}{ }^{-2}$. The current density in the cyclic voltammetry had a similar value. Results are qualitatively similar for other current densities. The working potential varied in a range of 2.1-3.5 V (Ag/AgCl) with electrodes containing different amounts of nickel dopants,.

\subsection{Materials and Chemical Analysis}

The concentration of 4-CP during the degradation process was determined by an UVspectrometer (Lambda 20, Perkin Elmer) (Stoyanova et al., 2003). The 279 nm peak was used in preference since the $225 \mathrm{~nm}$ peak was not linear at low concentration. The initial 4-CP concentration was too high with an off-scale signal and hence $0.1 \mathrm{~mL}$ solution sample was withdrawn and diluted 30 times for UV detection. The organic concentration in the solution was measured by a total organic carbon (TOC) analyzer (TOC-5000A, Shimadu) based on the combustion-infrared method. A $2 \mathrm{~mL}$ sample of the solution was withdrawn and diluted 20 times for the TOC measurement. Since solutions were withdrawn, the EC action will be more concentrated on the remaining solution. To avoid this error, fresh solutions of equal volume were used for each data point and EC was applied for different time intervals before samples were withdrawn for UV and TOC determinations. To check the accuracy of the determination of 4-CP concentration by UV spectroscopy, liquid samples after different periods of electrolysis were also analyzed by high performance liquid chromatography. A Waters high performance liquid chromatography (HPLC) instrument with 2695 separation module and 2996 photodiode array detector was used with 50\% methanol in water as the

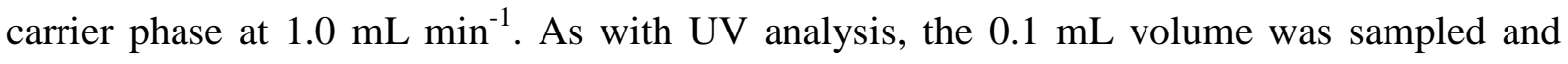


diluted to $3 \mathrm{~mL}$ for HPLC injection. The doped $\mathrm{SnO}_{2}$ electrodes were characterized for their cyclic voltammetry in the electrolyte of $0.1 \mathrm{M}$ sulfuric acid with and without the addition of 8 $\mathrm{mM}$ 4-CP, at room temperature and a scan rate of $50 \mathrm{mV} \mathrm{s}^{-1}$. The electrode surface was

4 observed with a scanning electron microscopy (SEM) (LEO1530, LEO Electron Microscopy). x-ray photoemission spectrometry (XPS) measurement was performed on a SKL-12 spectrometer with a vacuum generators CLAM4 multi-channel hemispherical analyzer using the Al-Ka excitation $(1486.6 \mathrm{eV})$. The raw data were fitted with the accessory

8 software XPSPEAK 4.1. The C1s peak at $284.6 \mathrm{eV}$ was chosen as reference for the peak location calibration. In addition, the resistivity of the doped $\mathrm{SnO}_{2}$ film was measured with the LORESTA-GP MCP-T600 4-probe resistivity meter (Mitsubishi Chemical). Some of the properties of the electrodes characterized are listed in Table 1.

12

\section{Results and Discussion}

\subsection{Characterization of the electrodes}

The electrodes prepared by the deposition of $\mathrm{SnO}_{2}$-Sb-Ni have a smooth surface according to the SEM micrograph (Fig. 1). The electrodes are uniformly covered by $5-10 \mathrm{~nm}$ particles. There are no obvious defects and cracks of the coating layer found on the electrode surface. Since the location of the Sb and Sn lines overlap in the EDX spectra, SEM-EDX was not used to analyze the electrode surface. A typical full-width XPS spectrum of the electrode $\mathrm{Ni} 2$ is showed in Fig. 2 which highlights the abundance of C1s, $\mathrm{Sn}_{5 / 2}, \mathrm{Sn}_{3} \mathrm{~d}_{3 / 2}, \mathrm{O} 1 \mathrm{~s}$ and $\mathrm{Sb}_{3 / 2}$. Because of the overlapping of $\mathrm{O} 1 \mathrm{~s}$ and $\mathrm{Sb}_{3 / 2}$ lines, the $\mathrm{Sb}_{3 / 2} \mathrm{~d}_{3 / 2}$ line is used to determine the $\mathrm{Sb}$ concentration based on the assumption that peak areas of $\mathrm{Sb}_{5 / 2}$ and

24 Sb3d $_{3 / 2}$ has a fixed ratio at 1.44 (Zhang and Gao, 2004; Montilla et al., 2004). The Sn, Sb and Ni contents in the electrode surface composition from the XPS analysis are summarized in 
Table 1. For all the electrodes samples, the $\mathrm{Sb}_{3 / 2}$ peak located at $540.0 \pm 0.1 \mathrm{eV}$, which indicated that almost all $\mathrm{Sb}$ existed in the valence of $\mathrm{Sb}(\mathrm{V})$. The $\mathrm{Ni}_{2} \mathrm{p}_{3 / 2}$ peak located at 855.6 $\pm 0.1 \mathrm{eV}$, which indicates that almost all $\mathrm{Ni}$ was in the valence of $\mathrm{Ni}(\mathrm{III})$. For electrodes

4 of different Ni doping ratios, the binding energy of $\operatorname{Sn} 3 \mathrm{~d}_{5 / 2}$ and $S n 3 \mathrm{~d}_{3 / 2}$ differed to a certain extent. It should be noted that although the $\mathrm{Sb}$ was $1.6 \%$ of $\mathrm{Sn}$ in the precursor coating solution, the Sb content in the coating film of the electrodes was higher than that in the coating solution. Also, the Ni had a certain degree of enrichment in the coating surface. This

8 enrichment of the doping elements in the coating layers of the electrodes also has been observed by others (Zhang and Gao, 2004).

The linear sweep voltammograms of the electrodes with different Ni doping ratios in $0.1 \mathrm{M}$ sulfuric acid are given in Fig 3a. The onset potentials of an anodic current were all

12 higher than $1.7 \mathrm{~V}(\mathrm{Ag} / \mathrm{AgCl})$. According to our previous studies, ozone could be produced in the order of $\mathrm{Ni} 2>\mathrm{Ni} 5>\mathrm{Ni} 10>\mathrm{Ni} 0$ at a potential higher than $1.7 \mathrm{~V}$. Although the voltammograms showed similar onset potentials, electrode Ni2 had the fastest rise in current. Within the voltage range scanned, there were no peaks and shoulders found in the voltammograms of all electrodes and no cathodic currents were identified on the reverse scan.

The voltammograms in the electrolyte of $0.1 \mathrm{M}$ sulfuric acid with $8 \mathrm{mM} 4-\mathrm{CP}$ show new anodic peaks located at about 1.2-1.5 V for different electrodes (Fig. 3b). At this range of potential, peaks were not observed in the control experiment and oxygen or ozone evolution was not expected. Hence, these peaks suggest the direct anodic oxidation of 4-CP in the acidic media. The peak currents are 2.63, 4.22, 3.25 and $2.0 \mathrm{~mA} \mathrm{~cm}{ }^{-2}$ for electrodes Ni0, Ni2, Ni5 and Ni10, respectively, implying that the electro-oxidation activity of the four anodes for 4-CP oxidation lied in the order of $\mathrm{Ni} 2>\mathrm{Ni} 5>\mathrm{Ni} 0>$ Ni10. Trace amount of Ni doping (0.2\%) into the $\mathrm{SnO}_{2}$-Sb coating solution increased substantially the reactivity of the electrode towards organic oxidation. While cyclic voltammetry was performed, it was 
observed that the anodic oxidation of the organic was irreversible without any cathodic peaks on the reverse scan. Anodic peaks in subsequent cycles were lower. This could be due to removal of 4-CP by anodic degradation or more likely caused by contaminated adsorption of

4 oxidation products onto the electrode.

\subsection{4-CP degradation and TOC removal}

The concentration of 4-CP after different periods of electrolysis was analyzed by UV spectroscopy and TOC analyses. While the TOC analyses were reliable, it was found later that the UV results were affected by the presence of oxidation products, such as 4chlorocatechol (Brillas et al., 1998) and benzoquinone (Johnson et al. 1999; Rodrigo et al., 2001). These compounds also absorb UV at similar wavelengths. To determine the extent of this error, HPLC analyses were performed for the EC treated with the Ni-Sb doped $\mathrm{SnO}_{2}$ electrodes, in parallel to UV spectroscopy. The results in Table 2 show that the 4-CP concentration determined by UV absorption was inaccurate in the intermediate time interval

16 when there is significant amount oxidation intermediates produced and not yet further oxidized. The actual 4-CP concentration determined by HPLC was lower. At the beginning of electrolysis and at long time, the error was small since there were no oxidation products or they are completely removed. Therefore the UV results obtained for the various electrodes

20 after different periods of electrolysis were corrected by a calibration with respect to the HPLC results, based on Table 2. The relative error can be fitted into a sigmoidal curve and be applied to correct for the UV results. Figure 4 shows the effective of the EC process in reducing the 4-CP concentration. The 4-CP concentrations were determined by UV but corrected with consideration of the HPLC results of a typical run. 
As shown in Fig. 4, the electrodes with Ni-Sb doped $\mathrm{SnO}_{2}$ coatings were effective in EC oxidation of organic substances. The 4-CP concentration decreased continuously with the charge transferred during the degradation tests on different electrodes. The amount of $\mathrm{Ni}$ 4 doping on the electrodes had a considerable effect on the kinetics of 4-CP destruction by EC degradation. The 4-CP concentration reduced to zero with electrolysis on the Ni2 electrode after $115 \mathrm{C}$ of charge consumed, while on the Ni10 electrode, the 4-CP concentration was still $20 \mathrm{mg} \mathrm{L}^{-1}$.

The degradation of 4-CP by the Sb-Ni doped $\mathrm{SnO}_{2}$ EC process was closed to completion. The TOC concentration decreased to $10 \mathrm{mg} \mathrm{L}^{-1}$ on the Ni2 electrode after $144 \mathrm{C}$ consumed. Since the only carbon source is from 4-CP, the initial mass ratio of 4-CP:TOC is 129:72. Comparing the two sets of curves in Fig. 4, the initial decline of 4-CP was much more rapid than TOC since the degradation intermediates of 4-CP still contained most of organic carbons. The TOC decline was faster after there were sufficient intermediates produced. On the electrode without the Ni doping, the EC degradation was slower as the TOC concentration decreased to $15 \mathrm{mg} \mathrm{L}^{-1}$ after $205 \mathrm{C}$. However, an over-doping of $\mathrm{Ni}$ at $16 \quad 1.0 \%$ on the Ni10 electrode appeared to have an adverse effect on its reactivity for 4-CP degradation compared to the case with the Ni2 electrode. A charge of $230 \mathrm{C}$ was consumed before the TOC was reduced to $14 \mathrm{mg} \mathrm{L}^{-1}$ on the Ni10 electrode. The effectiveness of the different electrode compositions can also be compared by fitting the degradation of 4-CP with first order kinetics. The first few data points near initial concentration were re-plotted in a semi-log plot to obtain the rate constant by a linear fit. The resulting first order rate constants of different electrodes are tabulated in Table 1. Electrode Ni2 has the highest rate constant of $0.020 \mathrm{~min}^{-1}$ or $0.0274 \mathrm{C}^{-1}$ for the degradation at $4 \mathrm{~mA}$ applied to an initial concentration of $1028 \mathrm{mg} \mathrm{L}^{-1}$ of $4-\mathrm{CP}$ in the $3 \mathrm{~mL}$ volume. 
Though nearly complete 4-CP destruction could be achieved for all four types of electrodes, the destruction efficiency in relation to the charge consumption was different 4 considerably for different electrodes. The electrochemical efficiency $\left(E_{C P}\right)$ for 4-CP destruction is defined as

$$
E_{C P}=\frac{\left(C P_{0}-C P\right) V}{C}
$$

where $C_{0}-C P$ is the change in the 4-CP concentration during the EC treatment test for a

8 charge consumption of $C$, and $V$ is the sample volume ( $3 \mathrm{~mL}$ ). Similarly, the TOC removal efficiency $\left(\mathrm{E}_{\mathrm{TOC}}\right)$ is defined as:

$$
E_{T O C}=\frac{\left(T O C_{0}-T O C\right) V}{C}
$$

where $T O C_{0}-T O C$ is the change in TOC concentration during the degradation test.

The charge efficiency changed with time when the concentration left in the solution decreased. The charge efficiencies at different final concentrations were calculated in reference to the initial concentration and are plotted in Fig. 5 for different electrode compositions. The charge efficiencies decreases monotonically with concentration for the 16 degradation of 4-CP. The high effectiveness of electrode Ni2 for 4-CP destruction was more obvious compared to the performance of other electrodes for the initial 4-CP destruction. The charge efficiency of TOC removal rises slowly until 4-CP is sufficiently degraded and attains a maximum value before falling off prior to complete degradation. Initial breakdown of 4-CP is needed before the removal of organic carbons. The highest efficiency is about 15 $\mu \mathrm{g} \mathrm{C}^{-1}$ for the Ni2 electrode when TOC has been degraded to $130 \mathrm{mg} \mathrm{L}^{-1}$. Again the same trend of comparison can be found among the different electrode compositions. The efficiency for organic removal on the Ti electrodes lied in the order of Ni2 $>\mathrm{Ni} 5>\mathrm{Ni} 0>\mathrm{Ni} 10$ in 
relation to the Ni doping ratio into the coating solution. This is the same order of the reactivity identified from the voltammetry curves towards 4-CP oxidation (Fig. 3b).

The experimental results demonstrated that the electrode coated with $\mathrm{Sb}$ doped $\mathrm{SnO}_{2}$

4 of the specific atomic ratio was effective in treating 4-CP to nearly complete degradation. Further doping of a trace amount of Ni doping could further enhance the reactivity of the Sb$\mathrm{SnO}_{2}$ electrode for the degradation of organic pollutants. There is a strong correlation of the composition of the coating for effective ozone generation and effective EC degradation. The

8 ratio of Ni:Sb:Sn was optimized earlier according to ozone generation (Wang et al., 2005) and in that work, the ozone concentration was measured by UV absorption at $260 \mathrm{~nm}$ and the measurement was calibrated with the iodometric titration. The efficiency for ozone generation at these electrodes lied in the order of Ni2 $>$ Ni5 $>$ Ni10 $>$ Ni0. The generation of

12 ozone observed was about $1 \mathrm{mg} \mathrm{h}^{-1} \mathrm{~cm}^{-2}$ of electrode. The degradation may or may not be due to action of ozone, but ozone was not detected by UV in the EC experiment except at the very end when all the pollutants and had been degraded. Oxidation of 4-CP by ozone was reported previously (Trapido et al., 1997; Sauleda and Brillas, 2001). Therefore it is plausible that 16 indirect degradation through ozone generation can proceed in parallel with direct anodic oxidation. The enhancement of EC degradation by an optimum Ni concentration may mainly attributable to the enhanced generation of an ozone precursor, hydroxyl radical or other intermediates produced by initial steps of the anodic process. Trace Ni doping changed the 20 electronic binding energy of $S n 3 d_{5 / 2}$ and $S n 3 d_{3 / 2}$, as shown in Table 1 . The binding energy shifted to a higher value with the Ni doping, particularly for the Ni2 electrode. This variation of binding energy with $\mathrm{Ni}$ concentration correlates with the corresponding effectiveness of the EC degradation. This can support the hypothesis of hydroxyl radical or other oxidative 24 intermediates which are favorably produced with a higher electronic excitation. Considering that the hydroxyl radical $(\cdot \mathrm{OH})$ is the key precursor of electrolytic ozone generation (Wabner 
and Grambow, 1985), $\cdot \mathrm{OH}$ formation during the EC process was well expected from the Ni doped electrodes. In the present experimental study on 4-CP degradation, ozone was not detectable, particularly in the early stage of the tests. However, this should not undermine the 4 possibility of $\cdot \mathrm{OH}$ generation during the electrolysis of $4-\mathrm{CP}$ in the acidic media. A high concentration of 4-CP used in this study would react rapidly with $\cdot \mathrm{OH}$ radicals and hence hinder the formation of ozone molecules. In fact, ozone did become detectable in the later stage of the EC degradation tests on the Ni2 and Ni5 electrodes when the 4-CP concentration

8 decreased to $100 \mathrm{mg} \mathrm{L}^{-1}$ or below, which was consistent with our previous findings on the capability of trace Ni doped $\mathrm{SnO}_{2}$-Sb electrodes for ozone production. Thus, as a precursor of ozone formation, $\cdot \mathrm{OH}$ radicals were highly likely produced from anodic water electrolysis throughout the EC degradation process. The radical reactions with 4-CP and other organic intermediates would contribute to the enhancement of 4-CP destruction and TOC degradation observed for the electrodes with trace Ni doping.

It should be pointed out that, although Ni doping is beneficial to radical generation, over-doping of $\mathrm{Ni}$ is detrimental to the effectiveness of the electrodes for $\mathrm{EC}$ organic degradation. A high $\mathrm{Ni}$ doping ratio would dramatically increase the resistivity of the electrodes (Table 1). The Ni10 electrode could have a resistance about 100 times of that of the NiO electrode without Ni doping. According to this study on EC 4-CP degradation and our previous work on electrolytic ozone generation, the optimal Ni doping ratio is $0.2 \%$ to $\mathrm{Sn}$ in the coating solution for the improvement of $\mathrm{SnO}_{2}$-Sb electrodes. A further increase in $\mathrm{Ni}$ doping ratio would increase the electrode resistivity significantly, which would greatly offset any possible increase in the reactivity of the electrodes towards organic degradation and other EC reactions. 


\section{Conclusions}

A trace amount of Ni doping into the $\mathrm{SnO}_{2}$-Sb electrodes could enhance the reactivity of the electrodes towards electrochemical oxidation of organics. The optimal Ni content was

4 found at $\mathrm{Sn}: \mathrm{Ni}=500: 1$ in atomic ratio in the precursor coating solution. A higher doping ratio would reduce the effectiveness of the electrodes for organic degradation. Using the electrode prepared with the optimal Ni doping ratio for 4-CP degradation, the charge-based efficiencies were up to $89 \mu \mathrm{g} \mathrm{C}^{-1}$ for 4-CP destruction and $15 \mu \mathrm{g} \mathrm{C}^{-1}$ for TOC removal, which

8 were considerably higher than the efficiencies obtained for other electrodes either without the doping or with over-doping of Ni. It is suspected that the enhancement of the electrode with trace Ni doping for organic oxidation could be mainly attributed to the improvement in the production of hydroxyl radicals from anodic water electrolysis. Ni doped $\mathrm{SnO}_{2}$-Sb electrodes

12 are capable to produce more $\cdot \mathrm{OH}$ radicals, which are known as the precursors of ozone formation in the absence of organic molecules.

\section{Acknowledgments:}

This research has been supported by a seed funding from CRCG, a University Development Fund for Water Environment Engineering in the University of Hong Kong and a grant from the Research Grants Council of Hong Kong SAR (HKU7008/01E). The XPS analysis was performed at CSAR in Hong Kong Baptist University. 


\section{References:}

Borras, C., Laredo, T., Mostany, J., Scharifker, B.R., 2004. Study of the oxidation of solutions of p-chlorophenol and p-nitrophenol on Bi-doped $\mathrm{PbO}_{2}$ electrodes by $\mathrm{UV}$-Vis and

$4 \quad$ FTIR in situ spectroscopy. Electrochim. Acta. 49, 641-648.

Brillas, E., Sauleda, R., Casado, J., 1998. Degradation of 4-chlorophenol by anodic oxidation, electro-Fenton, photoelectron-Fenton and peroxi-coagulation processes. J. Electrochem. Soc. $145,759-765$.

8 Canizares, P., Garcia-Gomez, J., Saez, C., Rodrigo, M.A., 2003. Electrochemical oxidation of several chlorophenols on diamond electrodes - Part I. Reaction mechanism. J. Appl. Electrochem. 33, 917-927.

Cheng, S.A., Chan, K.Y., 2004. Electrolytic generation of ozone on an antimony-doped tin 12 dioxide coated electrode. Electrochem. Solid State Lett. 7, D4-D6.

Comninellis, C., 1994. Electrocatalysis in the electrochemical conversion/combustion of organic pollutants for waste-water treatment. Electrochim. Acta 39, 1857-1862.

Comninellis, C., Pulgarin, C., 1991. Anodic-oxidation of phenol for waste-water treatment. J. 16 Appl. Electrochem. 21, 703-708.

Correa-Lozano, B., Comninellis, C., De-Battisti, A.D., 1996. Electrochemical properties of $\mathrm{Ti} / \mathrm{SnO}_{2}-\mathrm{Sb}_{2} \mathrm{O}_{5}$ electrodes prepared by the spray pyrolysis technique. J. Appl. Electrochem. 26, 683-688.

20 Feng, Y.J., Li, X.Y., 2003. Electro-catalytic oxidation of phenol on several metal-oxide electrodes in aqueous solution. Water Res. 37, 2399-2407.

Grimm, J., Bessarabov, D., Maier, W., Stork, S., Sanderson, R.D., 1998. Sol-gel filmpreparation of novel electrodes for the electrocatalytic oxidation of organic pollutants in water. Desalination 115, 295-302. 
Houk, L.L., Johnson, S.K., Feng, J.R., Houk, R.S., Johnson, D.C., 1998. Electrochemical incineration of benzoquinone in aqueous media using a quaternary metal oxide electrode in the absence of a soluble supporting electrolyte. J. Appl. Electrochem. 28, 1167-1177.

4 Iniesta, J., Michaud, P.A., Panizza, M., Cerisola, G., Aldaz, A., Comninellis, Ch., 2001. Electrochemical oxidation of phenol at boron-doped diamond electrode. Electrochim. Acta $46,3573-3578$.

Johnson, D.C., Feng, J.R., Houk, L.L., 2000. Direct electrochemical degradation of organic 8 wastes in aqueous media. Electrochim. Acta 46, 323-330.

Johnson, S.K., Houk, L.L., Feng, J.R., Houk, R.S., Johnson, D.C., 1999. Electrochemical incineration of 4-chlorophenol and the identification of products and intermediates by mass spectrometry. Environ. Sci. Technol. 33, 2638-2644.

12 Kotz, R., Stucki, S., Carcer, B., 1991. Electrochemical waste-water treatment using high overvoltage anodes $\mathrm{I}$ : physical and electrochemical properties of $\mathrm{SnO}_{2}$. J. Appl. Electrochem. 21, 14-20.

Li, X.Y., Cui, Y.H., Feng, Y.J., Xie, Z.M., Gu, J.D., 2005. Reaction pathways and mechanisms of the electrochemical degradation of phenol on different electrodes. Water Res. 39, 1972-1981.

Lipp, L., Pletcher, D., 1997. The preparation and characterization of tin dioxide coated titanium electrodes. Electrochim. Acta. 42, 1091-1099.

Michaud, P. A., Panizza, M., Ouattara, L., Diaco, T., Foti, G., Comninellis, C., 2003. Electrochemical oxidation of water on synthetic boron-doped diamond thin film anodes. J. Appl. Electrochem. 33, 151-154.

Montilla, F., Morallon, E., De-Battisti, A., Barison, S., Daolio, S., Vazquez, J.L., 2004.

24 Preparation and characterization of antimony-doped tin dioxide electrodes. 3. XPS and SIMS characterization. J. Phys. Chem. B 108, 15976-15981. 
Pulgarin, C., Adler, N., Peringer, P., Comninellis, C., 1994. Electrochemical detoxification of a 1,4-benzoquinone solution in waste-water treatment. Water Res. 28, 887-893.

Quiroz, M.A., Reyna, S., Sanchez, J.L., 2003. Anodic oxidation of pentachlorophenol at $\mathrm{Ti} / \mathrm{SnO}_{2}$ electrodes. J. Solid State Electrochem. 7, 277-282.

Quiroz, M.A., Reyna, S., Martinez-Huitle, C.A., Ferro, S., De-Battisti, A., 2005. Electrocatalytic oxidation of p-nitrophenol from aqueous solutions at $\mathrm{Pb} / \mathrm{PbO}_{2}$ anodes. Appl. Catal. B-Environ. 59, 259-266.

8 Rodger, J.D., Jedral, W.J., Bunce, N.J., 1999. Electrochemical oxidation of chlorinated phenols. Environ. Sci. Technol. 33, 1453-1457.

Rodrigo, M.A., Michaud, P.A., Duo, I., Panizza, M., Cerisola, G., Comninellis, Ch., 2001. Oxidation of 4-chlorophenol at boron-doped diamond electrode for wastewater treatment. J. 12 Electrochem. Soc. 148, D60-D64.

Sauleda, R., Brillas, E., 2001. Mineralization of aniline and 4-chlorophenol in acidic solution by ozonation catalyzed with $\mathrm{Fe}^{2+}$ and UVA light, Appl. Catal. B-Environ. 29, 135-145.

Sharifian, H., Kirk, D.W., 1986. Electrochemical oxidation of phenol. J. Electrochem. Soc. 133, 921-924.

Stoyanova, M., Christoskova, S., Georgieva, M., 2003. Mixed Ni-Mn-oxide systems as catalysts for complete oxidation - Part I. Preparation and characterization. Appl. Catal. AGen. 249, 285-294.

20 Stucki, S., Kotz, R., Carcer, B., Suter, W., 1991. Electrochemical waste-water treatment using high overvoltage anodes II: anode performance and applications. J. Appl. Electrochem. 21, 99-104.

Theurich, J., Lindner, M., Bahnemann, D.W., 1996. Photocatalytic degradation of 424 chlorophenol in aerated aqueous titanium dioxide suspensions: A kinetic and mechanistic study. Langmuir 12, 6368-6376. 
Trapido, M., Veressinina, Y., Hentunen, J.K., Hirvonen, A., 1997. Ozonation of chlorophenols: Kinetics, by-products and toxicity. Environ. Technol. 18, 325-332.

Vicent, F., Morallon, E., Quijada, C., Vazquez, J.L., Aldaz, A., Cases, F., 1998.

4 Characterization and stability of doped $\mathrm{SnO}_{2}$ anodes. J. Appl. Electrochem. 28, 607-612.

Wabner, D., Grambow, C., 1985. Reactive intermediates during oxidation of water at lead dioxide and platinium-electrodes. J. Electroanal. Chem. 195, 95-108.

Wang, Y.H., Chan, K.Y., Cheng, S.A., Li, X.Y., 2005. Electrolytic generation of ozone on

8 antimony and nickel doped tin oxide electrode. J. Electrochem. Soc. 152, D197-D200.

Zanta, C., Michaud, P. A., Comninellis, C., De-Andrade, A.R., Boodts, J.F.C., 2003. Electrochemical oxidation of p-chlorophenol on $\mathrm{SnO}_{2}-\mathrm{Sb}_{2} \mathrm{O}_{5}$ based anodes for wastewater treatment. J. Appl. Electrochem. 33, 1211-1215.

12 Zhang, J., Gao, L., 2004. Synthesis and characterization of antimony-doped tin oxide (ATO) nanoparticles by a new hydrothermal method. Mater. Chem. Phys. 87, 10-13.

Zhi, J., Wang, H., Nakashima, T., Rao, T.N., Fujishima, A., 2003. Electrochemical incineration of organic pollutants on boron-doped diamond electrode: Evidence for direct 16 electrochemical oxidation pathway. J. Phys. Chem. B 107, 13389-13395. 


\section{Figure Captions}

Fig. 1. Scanning electron micrograph of a typical electrode.

Fig. 2. A typical full-width XPS spectrum of the Ni2 electrode.

Fig. 3. Linear sweep voltammograms obtained at room temperature and a scan rate of $50 \mathrm{mV}$

$\mathrm{s}^{-1}$ in an acidic electrolyte containing (a) $0.1 \mathrm{M} \mathrm{H}_{2} \mathrm{SO}_{4}$ and (b) $0.1 \mathrm{M} \mathrm{H}_{2} \mathrm{SO}_{4}$ and $8 \mathrm{mM}$ 4-CP.

Fig. 4. Electrochemical degradation of 4-CP with the charge consumed. (solid symbols represent $4-\mathrm{CP}$ concentration and hollow symbols represent TOC concentration. A $4 \mathrm{~mA}$ current was applied to $3 \mathrm{~mL}$ of 4-CP solution with $0.1 \mathrm{M} \mathrm{H}_{2} \mathrm{SO}_{4}$ at room temperature.)

Fig. 5. Comparison of the charge-based average efficiency as a function of the final concentration for (upper panel) 4-CP destruction and (lower panel) TOC removal. (The results are derived from the data given in Fig. 4). 


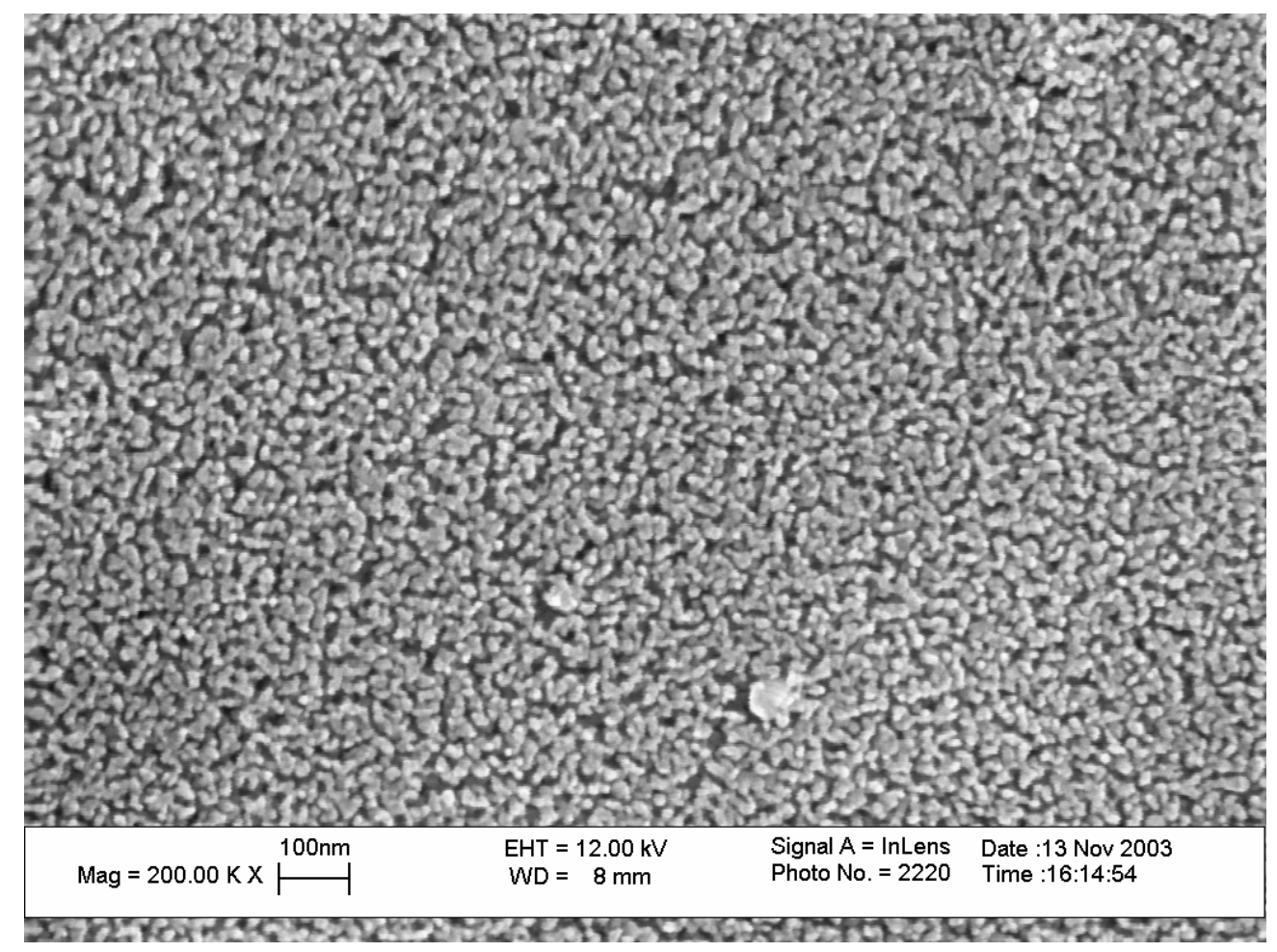

Fig. 1. Scanning electron micrograph of a typical electrode. 


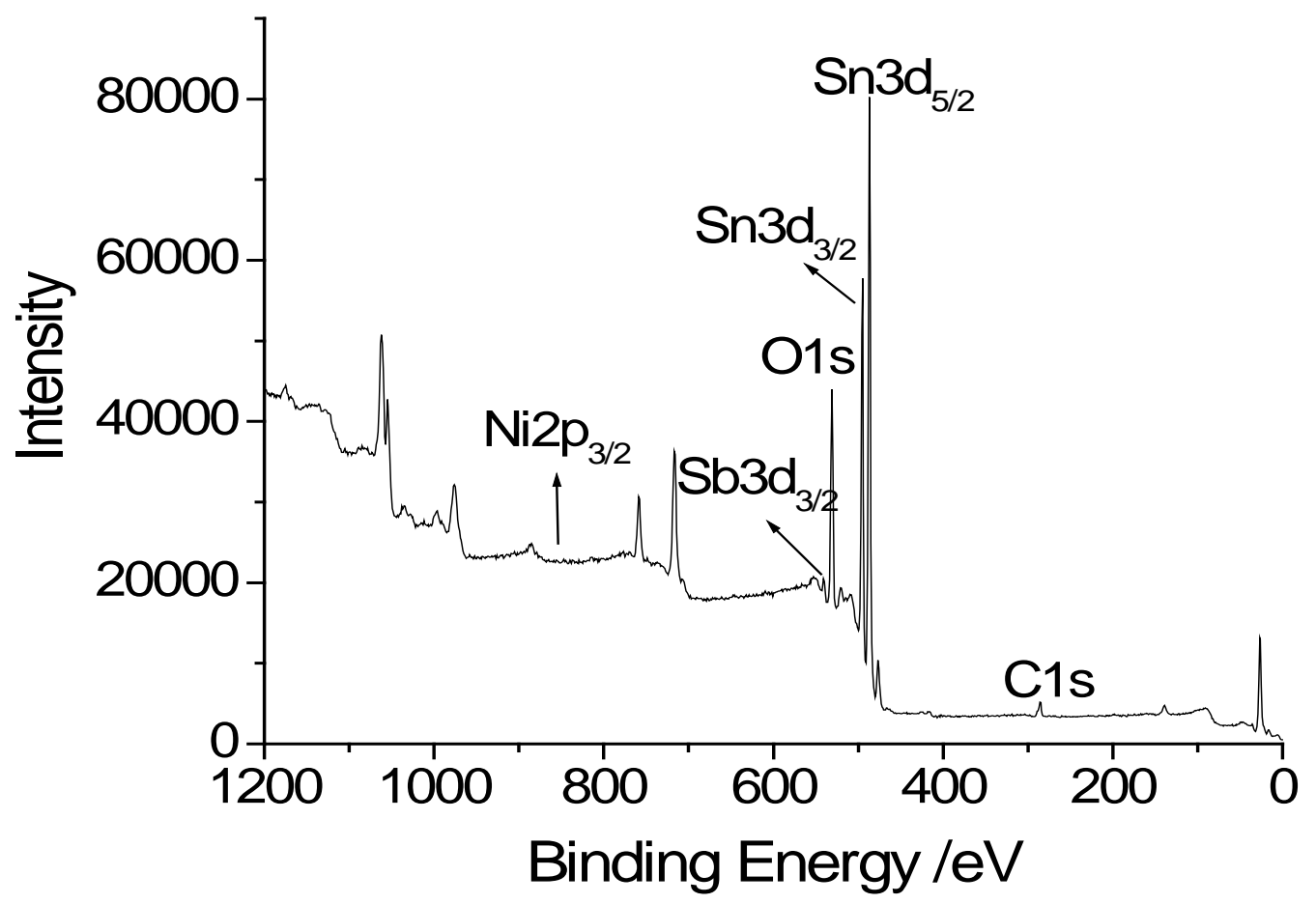

Fig. 2. A typical full-width XPS spectrum of the Ni2 electrode. 

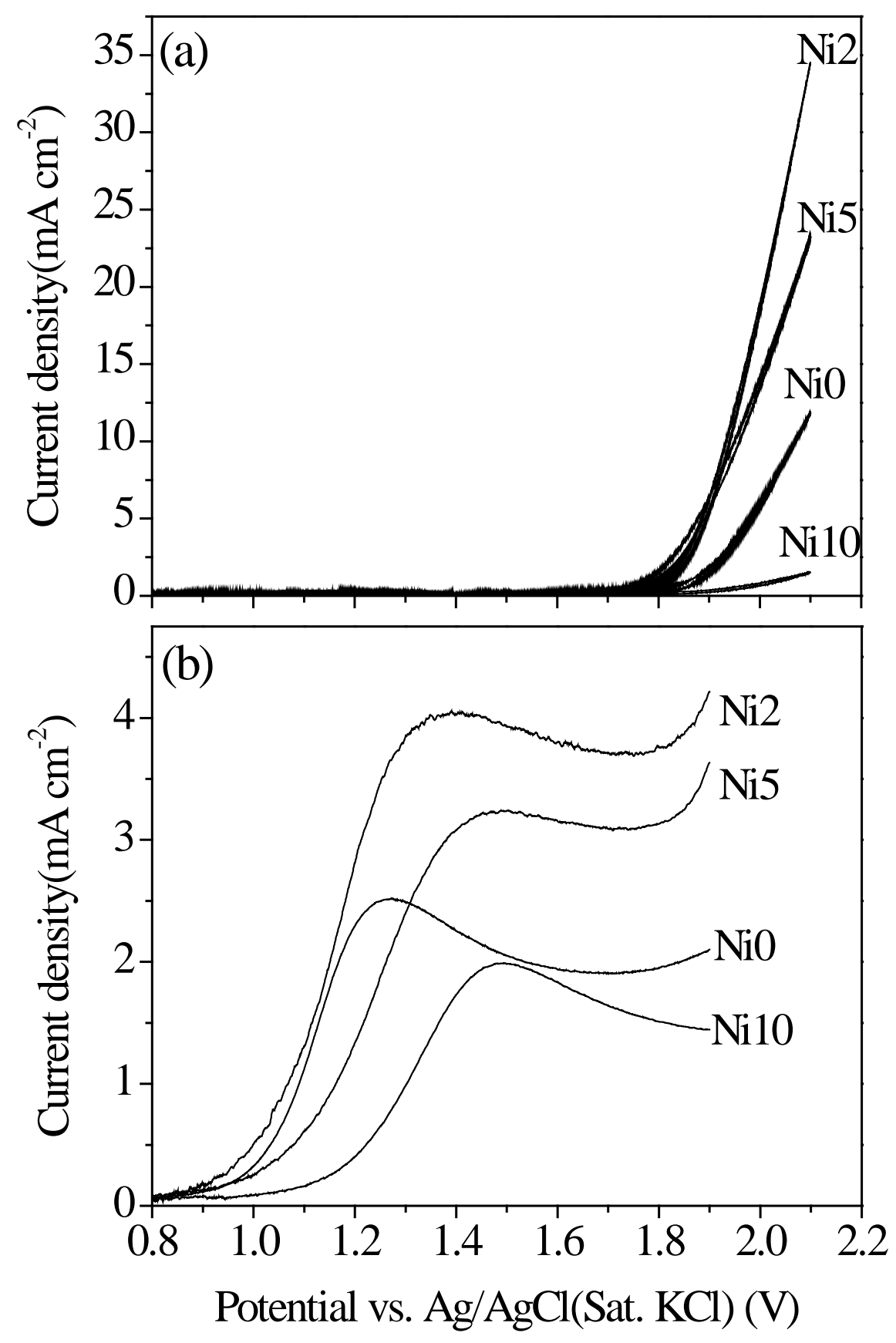

Fig. 3. Linear sweep voltammograms obtained at room temperature and a scan rate of $50 \mathrm{mV}$ $\mathrm{s}^{-1}$ in an acidic electrolyte containing (a) $0.1 \mathrm{M} \mathrm{H}_{2} \mathrm{SO}_{4}$ and (b) $0.1 \mathrm{M} \mathrm{H}_{2} \mathrm{SO}_{4}$ and $8 \mathrm{mM}$ 4-CP. 


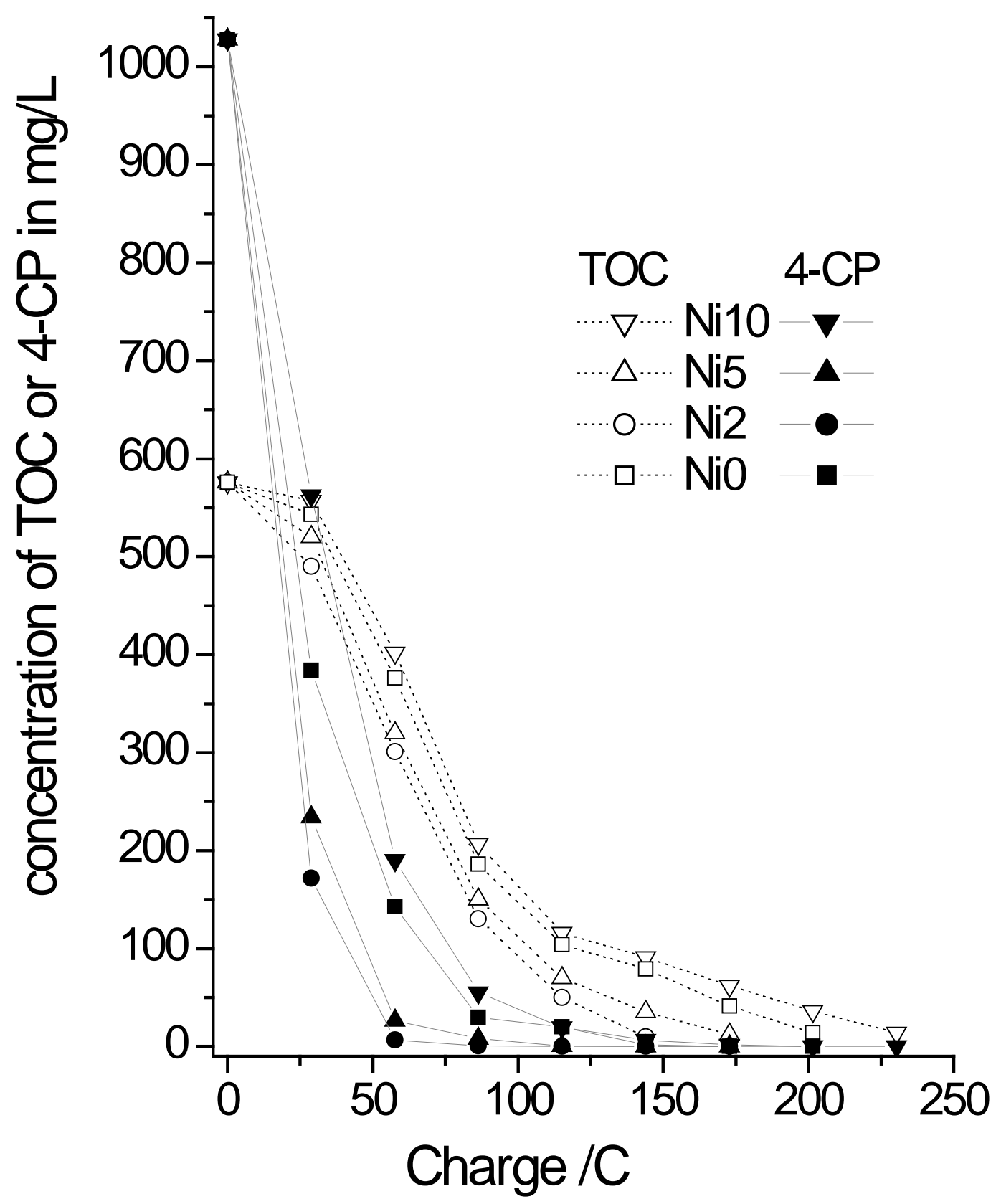

Fig. 4. Electrochemical degradation of 4-CP with the charge consumed. (solid symbols represent 4-CP concentration and hollow symbols represent TOC concentration. A $4 \mathrm{~mA}$ current was applied to $3 \mathrm{~mL}$ of 4-CP solution with $0.1 \mathrm{M} \mathrm{H}_{2} \mathrm{SO}_{4}$ at room temperature.) 

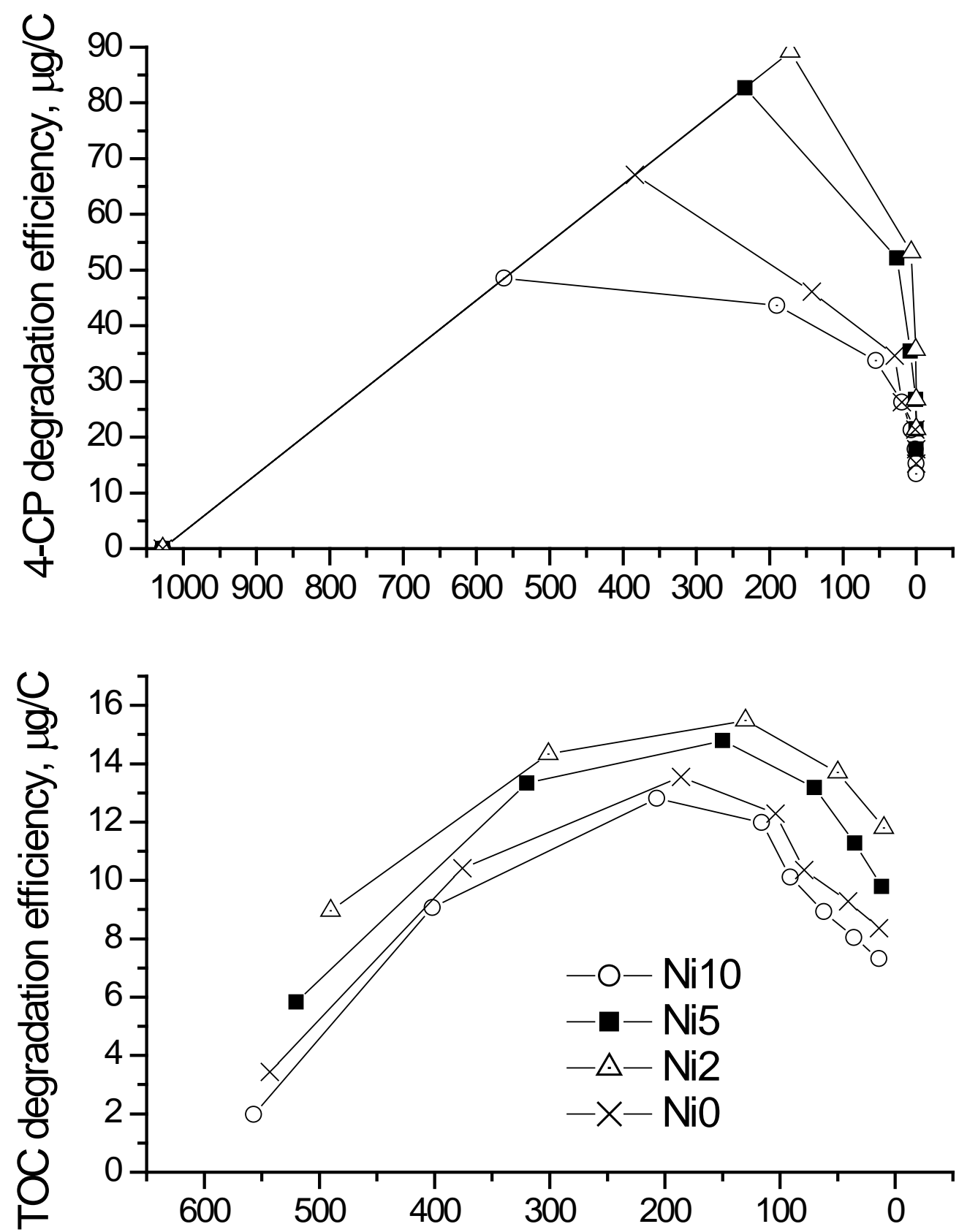

Final concentration, $\mathrm{mg} / \mathrm{L}$

Fig. 5. Comparison of the charge-based average efficiency as a function of the final concentration for (upper panel) 4-CP destruction and (lower panel) TOC removal. (The results are derived from the data given in Fig. 4). 
Table 1. Coating film compositions and binding energies based on the XPS analysis and other properties of the electrodes.

\begin{tabular}{|c|c|c|c|c|c|c|}
\hline Electrode & $\begin{array}{l}\text { Sn3d }_{5 / 2} \\
\text { binding } \\
\text { energy } \\
(\mathrm{eV})\end{array}$ & $\begin{array}{l}\text { Sn3d }_{3 / 2} \\
\text { binding energy } \\
(\mathrm{eV})\end{array}$ & $\begin{array}{l}\mathrm{Ni} /(\mathrm{Sn}+\mathrm{Sb}+\mathrm{Ni}) \\
(\%)\end{array}$ & $\begin{array}{l}\mathrm{Sb} /(\mathrm{Sn}+\mathrm{Sb}+\mathrm{Ni}) \\
(\%)\end{array}$ & $\begin{array}{l}\text { Resistivity } \\
\left(\Omega \mathrm{cm}^{-1}\right)\end{array}$ & $\begin{array}{l}1^{\text {st }} \text { order rate } \\
\text { constant in } \\
\text { degradation } \\
\text { of } 4 \text {-CP at } \\
4 \mathrm{~mA} \\
\left(\mathrm{~min}^{-1}\right)\end{array}$ \\
\hline $\mathrm{Ni} 0$ & 486.21 & 494.62 & 0 & 2.86 & 0.2 & 0.010 \\
\hline $\mathrm{Ni} 2$ & 486.89 & 495.32 & 0.71 & 4.67 & 0.6 & 0.020 \\
\hline Ni5 & 486.55 & 494.95 & 0.85 & 4.02 & 2.0 & 0.015 \\
\hline Ni10 & 486.45 & 494.91 & 1.64 & 3.59 & 20 & 0.009 \\
\hline
\end{tabular}

Table 2. Comparison of UV and HPLC analyses of liquids sampled after various periods of electrolysis.

\begin{tabular}{|l|l|l|l|l|}
\hline $\begin{array}{l}\text { Sample } \\
\#\end{array}$ & $\begin{array}{l}\text { Electrolysis time } \\
(\mathrm{h})\end{array}$ & $\begin{array}{l}\text { Charge passed } \\
(\mathrm{C})\end{array}$ & $\begin{array}{l}\text { 4-CP concentration } \\
\text { determined by UV } \\
\left(\mathrm{mg} \mathrm{L}^{-1}\right)\end{array}$ & $\begin{array}{l}\text { 4-CP concentration } \\
\text { determined by HPLC } \\
\left(\mathrm{mg} \mathrm{L}^{-1}\right)\end{array}$ \\
\hline 1 & 0 & 0 & 1213 & 1213 \\
\hline 2 & 1 & 14.4 & 944 & 740 \\
\hline 3 & 2 & 28.8 & 787 & 450 \\
\hline 4 & 3 & 43.2 & 656 & 211 \\
\hline 5 & 4 & 57.6 & 506 & 95 \\
\hline 6 & 5 & 72 & 399 & 32 \\
\hline 7 & 6 & 86.4 & 293 & 11 \\
\hline 8 & 8 & 115.2 & 112 & 0 \\
\hline 9 & 9 & 129.6 & 39 & 0 \\
\hline 10 & 10 & 144 & 1 & 0 \\
\hline
\end{tabular}

